\title{
Teaching Primary School Pupils Through Audio-Visual Means
}

\author{
$\underline{\text { https://doi.org/10.3991/ijet.v14i22.11760 }}$ \\ Sabdenova Bagila ${ }^{(\varpi)}$ \\ Kazakh National Women's Teacher Training University, Almaty, Kazakhstan \\ boken 888@mail.ru \\ Abdullah Kok \\ Akdeniz University, Antalya, Turkey \\ Aziya Zhumabaeva \\ KazNPU named after Abay, Almaty, Kazakhstan \\ Zharkynbike Suleimenova, Asima Riskulbekova \\ Kazakh National Women's Teacher Training University, Almaty, Kazakhstan \\ Uaidullakyzy Elmira \\ KazNPU named after Abay, Almaty, Kazakhstan
}

\begin{abstract}
Recognition of Kazakh language as the state language of the Republic of Kazakhstan by the Constitution of the Republic of Kazakhstan, adoption of 'State programme of functioning and development of languages for 2011-2020', the Law of the Republic of Kazakhstan 'On languages of the Republic of Kazakhstan', 'The State programme on education and science development for 2016-2020' allowed our native language to develop and prosper. Nowadays, special attention is paid to the problem of teaching the Kazakh language. In today's organized pedagogical environment, it is not fully examined the need for the development of communication skills of elementary school students and scientifically-based and practical communication to solve this problem via audio and graphic tools. Therefore, this article focuses on the need to teach elementary school students to work with audio and graphic materials and technology issues on the use of practical materials. Provided that the theoretical foundations for the development of communication skills of elementary school students through audio-visual aids hold true, the structuralsubstantial model will allow the development of each student's individual abilities and creativity. Taking into account the foregoing, we have set up a positive outline of the effectiveness of the work with audio equipment through the organization of practical work, practice-assemblage, research, diagnostics, practical work in elementary school teachers through specially organized thematic seminars.
\end{abstract}

Keywords - Audio technology, a teacher, audio-visual aids, communicative skills. 


\section{Introduction}

Orientation of modern pedagogy on the humanisation of the educational process causes actual problems of the creation of optimum conditions for personal development of each child, his/her personal self-determination. This problem is particularly relevant for primary schoolchildren since the results of psychological and pedagogical research have shown that in recent times, the processes of personal development and self-determination of children of this age have become more complex. This is based on the imperfection of their emotional-volitional sphere, the delay in the formation of the system of social relations, age identification and problems of family education. The situation of education in a modern school requires a child to actively solve new complex language problems, the main of which is the ability of pupils to establish business relations with each other and with a teacher on the studied material. The formation level of language skills contributes not only to the effectiveness of training but also to socialisation and development of pupils in general. Therefore, it is very important for a pupil to develop the highest forms of communication with adults and peers. This creates prerequisites for the formation of a new type of relationship between a pupil and a teacher, classmates.

The article deals with the ability of primary school pupils to communicate, possess abilities that cause it, it is considered in detail to communicate through messages, the relation between a teacher and a pupil, communicative skills, on the way to achieve this goal, the role of the teacher will be shown in organising and conducting the educational process.

The content of the updated knowledge requires the teacher to organise activities that enable the development of individual skills and creativity of each student in the classroom through the introduction of interactive technologies, the principle of humane attitude to children. In order to use all the opportunities of teaching strategies, a contemporary teacher shall have a diverse toolkit to combine different pedagogical approaches [1]. In addition, audio-visual equipment which includes audio technics, will allow for the implementation of all sounds of audiovisuals in the formulation of vocal skills and will enable them to provide instructional information in the natural language form in the teaching of listening and speaking and will contribute to the development of the learning process [2].

The updated content of education requires the teacher to organise activities that ensure the development of individual abilities and creative attitude of each student in the classroom through the introduction of activity technologies, the implementation of the principles of moral communication with children. For a modern teacher, it is necessary to have different arsenals in combination with different pedagogical approaches to use all the possibilities of the learning strategy. In comparison with the existing training programmes, recommendations for the teacher on the use of various methods, technologies and strategies in the successful achievement of the learning goals of the updated educational programmes are presented.

For example:

- Strategies: Self-directed, experimental, critical, communicative, contextual 
- Technologies: Work in small groups (team), case studies (analysis of specific situations), role and business games, modular training

- Methods: Problem-based learning, individual learning, inter subject communication, experience-based learning, project method [1]

The future of the country - the need for education and training of modern learners in accordance with modern requirements, has been even set out in the state compulsory standard of primary education. It is in the section of the standard 'Requirements for educational activities': 'the purpose of primary education is to create a favourable educational space for the harmonious formation and development of the learner's personality, possessing the following extensive skills:

- Being able to use knowledge functionally and creatively

- Critical thinking

- Being able to conduct research

- Being able to use information and communication technologies

- Mastering various ways of communication, including speech skills

- Skills of the group and individual work

One of the key features of the communication process is the intention of the participants to influence each other and impact on the others' behaviour.

Summing up the above-mentioned features of the language process, it should be noted that language communication is not limited just to the dissemination of information. It is an active influence, perception and understanding of people in the process of communication [17][18].

Primary school pupils are quick-tempered, temperamental in communication, and as technology, they use non-verbal means of communication. They have poorly developed feedback and the relationship itself is extremely emotional. With age, such features in communication are gradually disappeared and they become more balanced, verbal, effective, thrifty, as well as feedback may be established [19][20].

Characteristics of effective communication: Good mutual understanding between the interlocutors, good understanding of the situation and correct understanding of the subject of communication.

The positional attitude to solving the problem of language skills is presented in the work of L.S. Vygostky, where he considers communication as a prerequisite for personal development and child upbringing.

According to L.S. Vygotsky's concept [3][21], the formation of children's language skills is one of the main tasks of school. After all, the effectiveness and quality of communication largely depend on the level of formation of language skills of the subjects of communication.

Primary class pupils satisfy their physical and spiritual needs in a convenient way to themselves and for people whom they communicate [25]. Difficulties in the development of new rules and norms of behaviour may arise due to unjustified restrictions and ultra-high self-control.

Primary school age is associated with the introduction of school education as the most systematic form of communication, joining to the teaching process as a leading 
activity in that period. It involves the transition from visual-figurative specific situational form to abstract thinking, to such skills as the definition of connections, discussion, generalisation of thoughts, summing up.

In ontogenesis, for the first time, there is a mastery of written speech, replacing oral speech, which is occurred due to the longer duration of a sentence, the increase in the number of secondary parts of the sentence. By the end of primary school, the skill of proper construction and coherence of thoughts is formed in accordance with the development of logical and linguistic functions of speech, reflection.

Descriptive-declarative form of speech is changed to discussions, arguments. Analysis of the features of the formation of receptive forms of speech activity shows the growing role of the mechanism of understanding the meaning in reading, the tendency to rely on the main idea of the text while listening, the ability to comprehend the entire content of the text, its structural and logical organisation.

It has also been established that the language structure has a positive effect on the memorisation of the listened text. For the first time, the differentiation of ways of influence on the interlocutor in communication was revealed in productive forms of speech activity and it was implemented in written and oral texts. However, it is much lower than in other age groups.

At the age of primary school, children's relations with adults, especially with the teacher, take on special importance since a student's social position is formed in a child of this age which includes his activities related to the transition to schooling, new relationships with adults and peers, preparation for new way of life and the mastery of knowledge. Along with the desire to study at school, a child has difficulties and contradictions associated with the inability to implement these tasks. The more an adult teaches a child to perform new actions, the more the pupil's interest in learning is strengthened, some positive motivation for learning is formed.

Based on the language process, verbal and non-verbal communications are distinguished. Verbal communication is carried out through speech communication. With the help of speech, we understand natural speech sounds, as well as phonetic signs, two main lexical and syntactic features of it. Speech is a universal means of communication through which the value of a message is given in the transmission of information.

Most part of the research is closely connected with the study of individual indicators of the formation of thoughts in the process of speech. It is the increase of vocabulary, the volume of speech (number of phrases), the complexity of the lexicalgrammatical structure of all speech and certain phrases, implementation of logical speech of the techniques, etc.

Before talking about the new teaching aids used in the teaching process of primary school, we give a description of them. Then, giving importance to their natural character, it is advisable to determine their didactic features and functions, i.e., their role and place in the teaching process. Only then can we say with certainty what means of training are necessary to solve didactic problems in accordance with the applied concept of training and the intended purpose.

The classification of teaching facilities used in primary school includes the following signs: 
- Method for receiving information (visual, audio, audio-visual, multimedia)

- Information display method (technical, non-technical)

- The study/description of visual images (static, moving))

- Method of use in the classroom (demonstration, handout) [4].

Technical teaching aids are systems, complexities, devices and apparatus used in the provision and processing of information in order to improve the efficiency of the teaching process.

The quality of training process at the school depends on the visibility and presentation of the material, the ability of the teacher to combine the word with the image using various technical means of training with significant didactic capabilities. These didactic possibilities are defined as follows:

- Be a source of information

- Rationalisation of the presentation of educational information

- Increasing the degree of clarity, clarification of concepts, events

- Organisation and direction of reception

- Enrichment of students' views, satisfaction of their interests

- Being able to fully respond to pupils' scientific and cultural interests and needs

- Formation of pupils' emotional attitude to educational information

- Increase pupils' interest in learning through unusual, new designs, technologies, machines, equipment

- Organisation of available material for the pupils from inaccessible material which cannot be imagined without the technical means of education

- Activation of pupils' cognitive interests, promoting conscious mastering of the material, development of thinking, spatial imagination, observation of pupils

- Being a tool for receiving, summarising, systematising and controlling knowledge

- Establishing a link between theory and practice

- Creation of favourable conditions for the application of the most effective forms and methods of education, implementation of the basic principles of unified pedagogical process and procedure (rules) of the teaching process

- Saving time, energy of teacher and learner as a result of the synthesis of educational information and increase tempo [5]. F

Modern technical means of education have been expanding opportunities of application of various methods and receptions of work with pupils taking into account their age features and level of development and readiness. For students of any category, training can not only be organised interesting and fully information-rich with the help of technical means, but also it can be organised in accordance with pupils' capabilities [6].

In the last decade, the nomenclature of textbooks has changed dramatically. New elearning tools such as: video, audio, CD-ROM drives, Internet have widely distributed instead of training films, film strips and a gramophone record.

The modern stage of society development is characterised by turning of computer technology into a powerful tool that is included in all spheres of human activity, creates a global information space and ensures the spread of information flow in 
society. An integral and important part of these processes is the computerisation of education. Depending on the principle of operation, computer technologies are divided into mechanical, electromechanical, optical, audio technical, electronic and integrated technical means of teaching.

Computer technologies are currently developing rapidly and contribute to the use of existing technology capabilities, including multimedia, hypertext, modelling, interactivity. One of the main aspects is interactivity, the ability to create a synchronous and asynchronous dialogue. Other types of technology, such as video technology, interactive TVs, also contribute to the emergence of a dialogue, but this dialogue takes place internally, only by the person himself or provides very limited opportunities. Computer technologies contribute to the dialogue level with other subjects, which significantly increases the activity of learners [7][23].

Teaching facilities, depending on the logic of the computer technique, are divided into different modes of operation through linear software operation, i.e., with a branched program which does not require feedback, depending on the quality and volume of feedback.

Computer animation is the art of creating images moving on the display screen. An artist draws only drawings that reflect the initial and final positions of moving objects, and the computer describes all the movements between these two drawings, performing pre-designated mathematical calculations necessary for the movement of the object. A set of such images that appear with a certain frequency one after another allows you to display images moving on the screen.

Nowadays the technical means of teaching are widely used in the study of academic disciplines at school. To date, an interesting practical experience has been accumulated; the scientific basis for its application has been developed. However, there were difficulties related to the emergence of the electronic calculating machine as a technical means of education [24] [25]. Its essence lies in the fact that traditional technical means of education have not become a source of daily use by all teachers, and according to modern requirements, educational process should be changed into new information and educational technologies through computer and multimedia means. For this purpose, modern technical capabilities should be available to facilitate harmonious access of each child to the information society. Computer technology is not an additional tool in teaching, it should become an integral part of it, significantly increasing the effectiveness of the pedagogical process as a whole.

A complex and slightly considered issue of today is the psychological peculiarities of human-machine interaction when using a computer as a means of education. With the help of computer programs, pupils perform tasks in the form of a game or in any interesting form, receive new information and fix new knowledge and skills. Computer increases the activity of pupils in the process of obtaining and mastering information [26].

The main advantage of computer technology is Internet access. That is, anyone can get access to extensive information in the relevant field of science. With the help of a computer, a pupil will be fully provided with modern materials [27].

When using a computer, there are several methodological and psychological problems. All learners cannot master the computer. This can lead to stress. According 
to the results of research and surveys conducted by scientists, $30 \%$ of pupils studying computer had high blood pressure, sleep was disturbed, diseases were complicated. The reason for such negative consequences may be the lack of comfortable conditions in computer classes (lack of light, noise).

If $35 \%-40 \%$ of pupils are interested in the work on the computer related to learning (there are no words about computer games), about $35 \%$ consider it 'useful' or 'necessary' business, then $7 \%-12 \%$ find it 'difficult', 'ineffective' business.

Thus, if we take into account the data of previous studies and draw conclusions, the possibility of an in-depth study of any science on the computer is not interested in some of the students; on the contrary, it scares them, underachievers-pupils absolutely exclude work on a computer. If there is no difficulty for middle-level pupils, a successful pupil will understand and appreciate its importance.

In the educational process, the activities of computer technology are diverse. They are characterised by the fact that they are conditional, mutually dependent, but are complementing each other.

Any activity is not fully characteristic of computer technology.

Functions of computer technology:

- Linguistic - information dissemination function.

- Management-forecasting the preparedness of pupils to perform tasks, organisation of its implementation, feedback as a result of the processes of perception and development of information and correction of these processes.

- Concentration - storing, grouping, systematisation of educational and educationalmethodical information. These processes are carried out through the collection, creation, storing and dissemination of photo and video recording information through new information technologies.

- Activities related to the processing of information received by pupils with the help of computer technology for research purposes, the search for teachers' ways to use technical means of education in the process of teaching and education, modelling the content of information and forms of information transmission.

The effectiveness of the use of computer technology is determined by three interrelated aspects of its provision: technical, methodological and organisational.

Multimedia is a combination of high-quality images on the computer screen with sound. Multimedia means are used in education, electronic information tools, etc. To make full use of multimedia capabilities, you must not only install special programs on your computer but also connect special devices.

No special recording tools such as a prop eraser and batteries for markers are required to work with an interactive whiteboard. You can also write on the board by hand selecting the ink colour. It is worth noting that the whiteboard does not connect directly to the network and does not pose any danger to pupils. Interactive whiteboard is as a regular board. It also has trays, installed special containers that are responsible for colours of pollutants and markers. Each container has optical sensors that determine which tool you received the tray from. If all markers and erasers are in their place, then when you touch your hand to the board, it seems that you are working with the mouse, for example, if you got a marker in your hand, you can write on the board. 
On the interactive whiteboard, you can also do the work that you do on the computer: you can type and save text, show movies and slides, search for necessary information on the Internet. An interactive whiteboard will help primary school teachers to effectively communicate information to learners.

Of course, you can work with all the necessary programs on your computer, unfortunately, the size of the screen does not allow all learners to participate in the work. But you can draw pupils' attention by showing these materials on an interactive whiteboard. For example, a teacher shows educational material by creating invisible links between objects on an interactive whiteboard. By clicking on objects, opens the following pages, revealing the training material in a wider volume, thus, as long as all the studied objects will be displayed on the board. Pupils firmly master the relationship of educational material. This is another possibility of visualisation on the interactive whiteboard during the verification of knowledge. Thus, the use of interactive whiteboard has an advantage for both teachers and learners. The teacher can store the required materials in a single file connected with hyperlinks. Audio and video files can be activated and freely controlled when needed via the panel. One can also save additions and corrections included in the file in the following lessons.

Multimedia technology is a set of tools, methods and techniques to develop, process, combine, represent different types of data using information and software.

Multimedia technology is a set of tools, methods and techniques that can be used to prepare, process, integrate and present different types of data using information and software. Multimedia impacts on the increasing role of scientific knowledge and innovative solutions as a source of information news, considers the possibilities of technological growth and creation of new intellectual technologies [8].

Depending on the nature of the information in computer technology, technical means of education are divided into screen, sound and screen-sound means.

On-screen learning tools contribute to the perception, assimilation, systematisation of educational material; however, their pedagogical effectiveness is largely dependent on methods of introduction in the educational process [9].

When assessing the place and role of on-screen learning tools in the system of learning tools, the didactic possibilities of various means should be considered in the learning process. The condition is that the content of each textbook used in training should have a certain content (information identity of the content of training) and should provide solutions to a specific methodological task (functional and didactic coincidence of goals and methods of training). The developed complex will not remain unchanged. Its development is based on the development of content, methods and means of training. The development of fundamental theoretical positions is impossible without active thinking of learners. On-screen learning tools in the organisation of this work serve as a logical, methodical and emotional basis for its implementation. It contributes to the accumulation of information, the identification of visible and other features, deepening the connection of the actual material with theoretical ones.

On-screen learning tools include: film-strip, diapositive, transparency, epi-objects, etc.

Sonic learning tools are devices that provide sound recording and listening. 
They are: tape recorder, tape, disc, language laboratory, etc.

The most important condition for the use of on-screen learning tools in the classroom is a comprehensive communication, taking into account interdisciplinary connections in the creation of on-screen audio learning tools. For this purpose, it is necessary to make individual methodical tasks taking into account the purpose of training for certain elements of the contents in each part of the program which needs to be mastered. On-screen and sonic learning tools allow deeper consideration of the content of educational subjects, organise active activities of pupils, transform teaching methods, transfer learners from one activity to another one. Thus, it contributes to the development of pupils' attention and interest in the studied issue, readiness to overcome the difficulties.

Technical possibilities of modern screen-sound learning tools when fixing and demonstration of real phenomena turn it into a source of sensual, visual material, 'the living vision'.

Screen-sound learning tools include: film-strips, educational films, educational television, audio and video recordings, etc.

Visual learning (means of vision) tools are material means of learning used in the educational process in order to form knowledge, skills, skills of pupils, to manage their cognitive activity, general development and education.

Three main groups of visual learning tools can be identified: natural objects; pictures and images of real objects and phenomena (artistic and figurative means of learning); description of objects and phenomena by symbol, word or phrases of natural and artificial languages in the world.

1. Group-related to natural objects:

- Objects and phenomena of objective reality for direct research (minerals, rocks, raw materials, industrial products, preparations of plants and animals, etc.)

- Technical means of education (reagents, devices, etc.), reflecting the phenomena of demonstration and laboratory research of natural substances)

- Materials and technical means of education which are necessary for the labour, graphic, tourist and tourist activities of pupils (wood, metal, plastics, glass, etc.)

- Measurement, control and painting tools, machinery and other technical devices [10].

2. Group: Artistic and figurative means of education-layouts, models, a fake, globes, etc.; planar tools - table, picture, photo, map, drawing [11].

3. Group: Description of objects and phenomena in the world by words or phrases of natural and artificial language:

- Scientific, reference, teaching and other literature for teacher 
- Textbooks, collections of exercises and tasks, control of testing, laboratory and labour work, programming and other written materials [11].

Compilers of a special group of technical means of training:

- Informational (used for transmitting and receiving information recorded on a tape or on a gramophone record) - film apparatus, tape recorders, electronic players, televisions, etc.

- Punch control cards, pvc records and other types of machinery

- Study guides-language laboratories, electronic calculating machine, etc [11].

These learning tools are important in the classroom by their openness and emotionality, diversity, the ability to use one of them in another period of training, suitability for solving several methodological problems.

Audio learning tools-Sound technical means. They contribute to the implementation of all types of sound perception in the formation of pronunciation skills, the provision of educational information in a natural language form in teaching listening and pronunciation, intensifying the learning process [11].

Types of audio learning tools: audio recordings, broadcasting devices, tape recorders, record players, audio-passive and audio-active devices of language laboratories.

According to UNESCO, while listening, a person remembers $15 \%$ of language information, and when viewing - $25 \%$, in the process of viewing and listening - $65 \%$ of information will be remembered by him.

Light and sound technical means of education are widely used in modern General education schools. Light-learning tools (video recorder, TV, graphic projector, multimedia projector, computer) provide visual information that performs a number of functions in the learning process. They are:

1. Language support

2. Facilitates memorisation, being the medium connecting the semantic and sound aspects of the word

3. Displays various situations on the screen for the formation of pronunciation skills

4. Functioning as a key, provides feedback.

The above-mentioned light and sound technical means are called audio-visual teaching aids.

Audio-visual teaching aids are for 'educational visual aids for the presentation of visual and auditory information' [Azimov, 2009:22].

There are three levels of possible using of audio-visual teaching aids: episodic, systemic, synchronous.

- Episodic level - the teacher uses technical means of teaching in some cases. 
- Systemic level-technical means of teaching is introduced in the specialised educational process by the teacher for the purpose of transformation of pupils' perception and increase in the volume of educational material.

- Synchronous level - teacher continuously uses technical means of education during the lesson or in any part.

Various requirements are imposed on audio-visual teaching aids: functional, pedagogical, ergonomic and aesthetic, economic.

- Functionality - the ability to provide the necessary mode of operation of the device (pitch of a sound and quality; tape's capacity of audio-visual teaching aids; minimum power consumption; versatility).

- Pedagogical-compliance of technical means of education with modern requirements, to forms and methods of the educational process.

- Ergonomic - convenience and safety of transportation; minimum number of actions when working with the device; noise level; convenience of inspection, repair and transportation.

- Aesthetic - combination of a form (visibility, volume and proportionality); integrity of structure; appearance.

- Economic - despite its high quality, it is not too expensive and long-lasting [9].

- Video fragments are effective to create problem situations.

It is convenient as an introductory material before setting the task. Sometimes by means of video fragments, supporting information is provided, leading to the question. In the fragment, one can specify the emergence of problem and how to solve it. It should be extracted from information that will surprise pupils and should be of interest in order to identify the truth.

In the movie, much attention is paid to animation, schematic images. The film will be able to convey to learners the complex phenomena, concepts, situations at an accessible level. It promotes pupils' understanding of the development of nature and society, to determine their attitude to the phenomena in the environment, the formation of scientific foundations of conscious reality. Films on academic disciplines reflect voluminous material, giving a generalised character. Such films can be used in introductory and final lessons.

Educational films are classified according to the discipline and individual methodology, the age of learners, the degree of scientific readiness (if there are senior grades) and didactic functions. Depending on the last character, it is classified as follows:

- Movies in short film service

- Educational programmes, holistic films to explain the curriculum, for the question asked; films that help to master the production skills (demonstration at a special training stand)

- Guidance films defining the essence of production rules 
- Introductory movies to familiarise with the main problem, goals, objectives of the discipline; final films for repetition of learning material and questions, found it difficult mastering [12].

Processing of film will allow to slow down the rapid processes, resulting in to make them visible, to enlarge small objects in order to get inside into the invisible phenomena, to take the viewer to another country, to show general and abstract concepts using moving images (animation).

Epiobjects-images, designed for the screen (drawings from a book, pictures, photos, texts, illustrations, etc.) or flat natural objects. They may be both black and white and colour.

Projection apparatus - optical devices for increasing the volume of various objects. They are: filmstrip, slide, transparency, epifilm, photography, pictures, $\mathrm{v}, \mathrm{ji}$ transparencies in a non-darkened environment, slide projectors, graphoprojects, epiprojects showing the model closeup.

Static projection apparatus can be used at all stages of the lesson: when checking the homework, update support knowledge, motivation of educational activity, the presentation of new material, development, generalisation and systematisation of the studied material. The content and method of application of on-screen learning tools are determined in accordance with the didactic objectives of the lesson.

Educational filmstrips are a series of images that appear through the film on the transparent (colourless) basis. It provides preliminary preparation of educational information and allocation of frames in accordance with the established procedure. They can be both black-and-white and colour, both voiced or soundless [13].

They are often used as illustrations in the development, generalisation and systematisation of educational material. They are used as reference tools for independent work, knowledge testing, oral and written work.

Using on-screen learning tools requires the proper organisation of the appropriate stage of the lesson. First of all, you need to prepare children to view the video. The most effective form of preparation is a teacher's conversation, consisting of 2-3 questions within the framework of that topic. The introductory word before showing the onscreen material should not last for a long time, just a few minutes. If the theme of the film is not familiar, then questions which connect concepts that are known and unknown will be asked. For example, in the case of a new topic about a distant region, a teacher will move to a new topic after he tells about the nature and features of his own region. The more familiar is a new topic, the shorter should be an introduction.

After the demonstration, the teacher creates a conversation with pupils. Then he can determine how they have learned the material and give additional information. During this period, it should be better to use other teaching aids. The time of displaying the tool is determined by the time of the task, the assimilation of educational material by students. Long-lasted demonstration gets tired learners, especially pupils of primary grades. As a rule, after the demonstration is completed, the on-screen tool is turned off and the conversation will be continued. If necessary, the movie will be shown again. At that time, students will tell themselves. 
The effective use of on-screen learning tools depends on the role of the teacher in the learning process. Students, based on clearly visible images, compare, analyse them under the guidance of the teacher, identify the main thoughts, sum up certain thoughts, summarise. Thus, the teacher organises a single process of imaginative perception and active mental activity of pupils.

Thus, audio-visual means of education contribute to a deeper understanding of the content of the subject, organisation of vigorous activity of pupils, the transformation of teaching methods, pupil's activity changing from one type to another, thus, development of learner's attention and interest in the topic, readiness to overcome the difficulties.

So, summing up, we can say that the effectiveness of audio-visual training is determined in accordance with the specific goals of teaching, objectives, training material, forms and methods of organisation of teachers and students' work, features, material and technical conditions and capabilities.

\section{Materials and Methods}

Elementary school teachers and students of gymnasium No. 148 and No.15 of Almaty city were the study subject.

To achieve the goal, we used the following methods: philosophical, psychological, pedagogical concepts of the formation of a person's activity, the gradual theory of mental activity; scientific concepts on development of information culture, selfdevelopment; questionnaire, comparative analysis, generalisation and mathematical processing of results based on scientific concepts of communication skills development.

During the study, the teachers answered the following questions:

- What additional tools do you use to develop listening comprehension skills in the learning process?

- How important are the auxiliary tools in the achievement of the lesson's objective?

- What skills do you think a listener develops in the classroom?

- On a scale from 1 to 10 , how would you rate the effectiveness of audio-visual aids at teaching?

- Do you use listening materials most efficiently to achieve the lesson's objective? Please specify?

- How many times do you think students should listen when working with the audio materials?

- How often do you think the listening assignments in the new generation textbook developed within the framework of the updated educational programme? Please provide two-three examples. 


\section{$3 \quad$ Research Results}

In the analysis of the results of the survey, $30 \%$ of the teachers stated that they could access the listening materials from the Internet. That said $25 \%$ of teachers were not aware of the importance of auxiliary tools. $41 \%$ of the respondents were aware of what skills can listening develop at students. The effectiveness of the visual aids in the learning process was estimated by the score of 45 to $4-6$ points. The question was whether the use of listening materials was as effective as possible for the purpose of learning. The fact that we could not get a concise answer to questions 6 and 7 is proof that teachers need methodical help.

In order to increase the effectiveness of the results, a coaching session on the theme 'Kazakh language' and a subject 'The role of listening skills in increasing the creative abilities of students in the Kazakh language' was held. Coaching was a practical lesson. Experience has shown that listening materials can be used effectively in learning the purpose of learning, combined with the most effective ways to stimulate interest. At the end of the coaching, it was concluded that teachers would increase the interest in the subject and the effectiveness of the lesson and that the students would influence their communicative, written and systematic delivery of their ideas.

In order to effectively use audio equipment in the learning process, we used the technique "Effective use of listening materials for the development of communication skills of primary school students.

The main feature of such methodology is that students learn to combine creative knowledge in work with listening materials.

Also, the number of students interested in working with audio-visual equipment has been identified. Comparative diagnostics of audio/video recordings of students in classroom use were made. As a result, students' skills and abilities to work with the listening materials have been identified.

4 A (25 students) and 4 B (26 students) grade students participated in the following experiment. Here, the students worked in pairs, depending on their abilities. The students worked based on the 'problem text' strategy. An example of a complex work on the ability to evaluate the character, to express his/her own point of view, to develop his/her own events through listening the text, is presented in the following way:

1. Listen and understand the text: In our childhood, (every) another boy dreamed of becoming a cosmonaut. It was the desire of many to see the stars and to travel to the unknown world. I am one of them. One day, my dad told me about the (secrets) of the celestial world, and then showed me the moon, the various stars and the images of the whole planet. At that time, it is difficult for me to express how my curiosity ran wild. Then I set myself a goal to become a cosmonaut at any cost. I was studying at a university where I was (looking) for such opportunity. To be a cosmonaut, you must, first of all, enjoy good health from nature. Then you have to keep training sessions for a day. Every day training is planned from (9 am to $6 \mathrm{pm})$. There you will meet the requirements for the master of sports, the strongest requirement. Because of the above two things, maybe after 6 years of intensive training, I 
finally got out to space. I was part of the International crew, and I was accompanied by representatives from (6) countries. We have a lot of experience and lessons learned from each other.

All of us have seen the (picture) of the Earth taken out of space. We know that the earth is a sphere. But everything in space is different. The sky looks like a palm. It is so subtle, small and unprotected. My view is that we have to care for the Earth. We do not yet realise its dignity. From space to land, my view of life and the (environment) has radically changed. I understand that we have to preserve the planet we inhabit. (Because) we are human beings.

2. Set a heading for the text

- The space world

- Dreams come true

- The Planet

3. What do we know about space? Write down your thoughts.

4. Complete blank spaces by listening to the information

5. Define parts of the text.

6. Make plans for text. Describe the content of the text by the plan.

7. Express your attitude toward the character.

8. Formulate a question for finding solutions based on the content of the text.

9. What is the main thing to become a cosmonaut?

- Knowledge

- Attitudes and intentions to achieve goals

- Human qualities

10. Write down the keywords in the text.

11. Write an essay on the subject 'Astonishing Space' based on the keywords Find and verify the tense of the verbs from the text

This text identifies the level of students' linguistic abilities.

The tasks above type are directed to the following results:

Table 1. Planned results

\begin{tabular}{|l|c|c|}
\hline \multicolumn{1}{|c|}{ Planned results } & Score \\
\hline $\begin{array}{l}\text { The total number of tasks -12 } \\
\text { Maximum score }-23 \\
\text { Time for task - 40 minutes }\end{array}$ & 1 & 1 \\
\hline Understand the basic idea of the text & 2 & 1 \\
\hline Understanding the basic idea of the text and making a theme & 3 & 2 \\
\hline Formulation of opinion and writing down & 4 & 2 \\
\hline Listening to the information correctly & 5 & 3 \\
\hline Defining parts of the text & 6 & 2 \\
\hline Making plans and retelling of the text & 7 & 1 \\
\hline Expression of opinion and evaluation & 8 & 2 \\
\hline Formulation of question directed to find a solution, answering questions & & 2 \\
\hline
\end{tabular}




\begin{tabular}{|l|c|c|}
\hline Expressing opinion & 9 & 3 \\
\hline Finding and extracting keywords & 10 & 1 \\
\hline Compliance with essay requirements & 11 & 3 \\
\hline Detection of verb tenses (present, past, future) & 12 & 2 \\
\hline
\end{tabular}

The results of students' performance were calculated on the following scale:

0-7 excellent;

8-14 upper-intermediate;

15-19 intermediate;

20-23 low.

The results of the above task showed that the students' communicative skills were shaped.

Compiling the results of the experimental stages, we have reached a positive result. Teaching the Kazakh language by means of audio-visual means will not only increase the cognitive activity of the students but also create a system of logical thinking and creative work.

We summarised the experimental results as follows:

Table 2. Developing students' communicative skills through listening to the materialAs a result of the study, the following conclusion was made:

\begin{tabular}{|l|c|c|c|c|c|}
\hline Grade & Students & \multicolumn{4}{|c|}{ The level of development of work with listening assignments } \\
\hline & & Low & Intermediate & Upper Intermediate & Excellent \\
\hline \multirow{2}{*}{$4 \mathrm{~B}$} & \multirow{2}{*}{27} & 1 & 7 & 14 & 5 \\
\cline { 3 - 6 } & $4 \%$ & $26 \%$ & $52 \%$ & $18 \%$ \\
\hline
\end{tabular}

To summarise, today's audio-visual equipment is a solid foundation. The effectiveness of their teaching materials is scientifically proven and is therefore considered as one of the trends in domestic pedagogy. This will allow the students to achieve high performance in the learning process.

As a result of the research, we concluded the following:

1. It is important to teach the understanding and implementation of the importance of the use of audio-visual aids in the learning process by elementary school teachers.

2. Development of a special methodology for the effective use of audio equipment in the learning process.

3. Students have the following disadvantages in developing communication skills:

- Defining the main idea of the text and formulating of opinion;

- Ability to prove conclusions;

- Subject knowledge, logical conclusion.

So, along with the above-mentioned arguments, we would like to say that there are other types of work that can be of interest to the subject. Example: effective use of interactive methods in the learning process. Here, students have the opportunity to 
make the most of their opportunities, such as adapting to the learning environment, critically thinking and self-development.

Summarising the research, we have reached a positive result. Teaching the Kazakh language by means of audio-visual means will not only increase the cognitive activity of the students but also create a system of logical thinking and creative work.

\section{$4 \quad$ References}

[1] (2016). Peculiarities of the Organization of the Educational Process in General Educational Institutions of the Republic of Kazakhstan in 2016-2017 Academic Year. Almaty, $257 \mathrm{p}$.

[2] The Use of Audiovisual Learning Tools at the Initial Stage. Available from: http://mirrorref.ru (accessed 02 November 2017).

[3] Vygotsky, L. S. (2004). Psychology of Child Development. M.: Smysl, Eksmo, 512 p.

[4] Noskova, T. N. (2004). Audiovisual Technologies in Education. SPbGUKiT, SPb.

[5] Lerner, I. Y. (2007). Didactic Basics of Teaching Methods. Moscow, 221 p.

[6] Talyzina, N. F. (1985). Psychological and Pedagogical Bases Of The Automation Of The Educational Process. Psychological, pedagogical and psychophysiological problems of computer training: Collection of scientific papers. M. publishing house of the USSR Academy of Pedagogical Sciences, Moscow State University, pp 15-26.

[7] Muldabekova, K. Ch. (2014). Formation of Communicative Competence of Future Specialists through Information Technologies. The dissertation for Doctor of Philosophy degree (PhD). Almaty, $149 \mathrm{p}$.

[8] Uaidullakyzy, E. (2014). Formation of Information and Professional Competence of Primary School Teachers. The dissertation for a Doctor of Philosophy degree (PhD). Almaty, $138 \mathrm{p}$.

[9] Matsutsa, K. I. (2006). The use of audiovisual teaching aids in computer science lessons. INFO (informatics and education), (7): 110-114.

[10] (2015). On amendments and additions to the Decree of the Government of the Republic of Kazakhstan of August 23, 2012 № 1080 "On approval of state educational standards of appropriate levels of education", Astana.

[11] Schukin, A. N. (1981). Methods of Using Audiovisual Aids. Russian Language, Moscow.

[12] Moshkalov, A. K. (2013). Self-creative Development of Students' on the Bases of Using Information and Communication Technologies. The dissertation for a Doctor of Philosophy degree (PhD), Almaty, $138 \mathrm{p}$.

[13] Moshkalov, A. K., Baimuhkanbetov, B. M., Baikulova, A. M., Anarbayev, A. K., Ibrayev, A. Z., Mynbayeva, A. P. (2018). The content-structure model of students' artistic selfdevelopment through the use of information and communications technology. Astra Salvensis - review of history and culture. VI (12): 363-383.

[14] Uaidullakyzy, E., Turalbayeva, A. T., Sultanbek, M., Utyupova, C. E., Aidarov, B. Z. (2017). The general preparation of the training of elementary school and the family and the education of gifted children school in cooperation principles. Ponte, 73(4): 239-251. https://doi.org/10.21506/j.ponte.2017.4.54

[15] Uaidullakyzy, E., Utegenov, Y., Assanova, U., Kilybayev, K., Muzdybayev, B. (2014). Formation of Information and Professional Competence of Primary School Teachers. Life Science Journal, 11: 133-140. 
[16] Sartayeva, N. T., Kenesbaev, S. M., Zhailauova, M. K., Uaidullakyzy, E., Nurzhanova, Stambekova A. S. (2018). Possibilities of the subject information and communication technologies in accustoming primary school students to research activities. International Journal of Interactive Mobile Technologies, 12(6): 35-46. https://doi.org/10.3991/ijim.v12i6.9622

[17] Kurniawan, W., Anwar, K., \& Kurniawan, D. A. (2019). Effectiveness of Using E-Module and E-Assessment. International Journal of Interactive Mobile Technologies, 13(9). https://doi.org/10.3991/ijim.v13i09.11016

[18] Nouri, J., Ebner, M., Ifenthaler, D., Saqr, M., Malmberg, J., Khalil, M., \& Berthelsen, U. D. (2019). Efforts in Europe for Data-Driven Improvement of Education-A Review of Learning Analytics Research in Six Countries. International Journal of Learning Analytics and Artificial Intelligence for Education, 1(1), 8-27.https://doi.org/10.3991/ijai. v1i1.11053

[19] Suartama, I. K., Setyosari, P., \& Ulfa, S. (2019). Development of an Instructional Design Model for Mobile Blended Learning in Higher Education. International Journal of Emerging Technologies in Learning, 14(16).https://doi.org/10.3991/ijet.v14i16.10633

[20] Chen, B., \& Wu, J. (2019). Promotive Effect of Psychological Intervention on English Vocabulary Teaching Based on Hybrid Collaborative Recommender Technology. International Journal of Emerging Technologies in Learning, 14(15).https://doi.org/10.39 91/ijet.v14i15.11185

[21] Turan Çimşir, B., \& Uzunboylu, H. (2019). Awareness training for sustainable development: Development, implementation and evaluation of a mobile application. Sustainability, 11(3), 611.

[22] Ozkal, N. (2019). Relationships between self-efficacy beliefs, engagement and academic performance in math lessons. Cypriot Journal of Educational Sciences, 14(2), 190-200. https://doi.org/10.18844/cjes.v14i2.3766

[23] Kasimatis, K., \& Papageorgiou, T. (2019). Using rubrics as alternative self-assessment technique of project. World Journal on Educational Technology: Current Issues, 11(3), 173-185. https://doi.org/10.18844/wjet.v11i3.4142

[24] Darmaji, D., Astalini, A., Kurniawan, D., \& Perdana, R. (2019). A study relationship attitude toward physics, motivation, and character discipline students' senior high school, in Indonesia. International Journal of Learning and Teaching,11(3), 99109.https://doi.org/10.18844/ijlt.v11i3.4207

[25] Dandashly, N., Barbar, A., \& Antoun, M. (2019). The effects of using blogs and webquests in teaching education postgraduate courses. Global Journal of Information Technology: Emerging Technologies, 9(1), 12-19.https://doi.org/10.18844/gjit.v9i1.4018

[26] Pastırmacioglu, B., Caliskan, S., Ozcan, D., \& Uzunboylu, H. (2018). Determining a Mobile Internet Acceptance Model of Special Education Teacher Candidates. International Journal of Interactive Mobile Technologies (iJIM), 12(4), 32-42.

[27] Uzunboylu, H., \& Altay, O. (2019). State of affairs in multicultural education research: a content analysis. Compare: A Journal of Comparative and International Education, 1-20. Published online: 06 Jun 2019, https://doi.org/10.1080/03057925.2019.1622408

\section{Authors}

Sabdenova Bagila, PhD Doctoral Student of Kazakh National Women's Teacher Training University, Almaty, Kazakhstan, boken_888@mail.ru. 
Abdullah Kök, Dr. Professor, Akdeniz University. Department of Turkish language and Literature, Akdeniz University, Antalya, Turkey abdullahkok07@,icloud.com.

Aziya Zhumabaeva, Doctor of Pedagogical Sciences, Professor of KazNPU named after Abay, Almaty, Kazakhstan, aziya_e@mail.ru.

Zharkynbike Suleimenova, Doctor of Pedagogical Sciences, Professor of Kazakh National Women's Teacher Training University, Department of the Kazakh Language, Almaty, Kazakhstan, zharkyn123@mail.ru.

Asima Riskulbekova, Candidate of Pedagogical Science, Senior Teacher of Department Pedagogy and Initial Training Methods, Kazakhstan, asima_78kz@mail.ru,

Uaidullakyzy Elmira, PhD, Senior Teacher of KazNPU named after Abay, Almaty, Kazakhstan, elmira uaidulla@mail.ru,

Article submitted 2019-09-24. Resubmitted 2019-11-05. Final acceptance 2019-11-05. Final version published as submitted by the authors. 